\title{
A EXPRESSÃO DE VERBOS MODAIS NA TRADUÇÃO DO GÊNERO DECISÃO: CONTRIBUIÇÕES PARA O ENSINO DE LÍNGỦA ESTRANGEIRA
}

\author{
LA EXPRESIÓN DE VERBOS MODALES EN LA TRADUCCIÓN DEL \\ GÉNERO DECISIÓN: CONTRIBUCIONES PARA LA ENSEÑANZA DE LENGUA \\ EXTRANJERA
}

\author{
THE EXPRESSION OF MODAL VERBS IN TRANSLATION OF \\ DECISION GENDER: CONTRIBUTIONS TO FOREIGN LANGUAGE \\ TEACHING
}

Viviane Cristina POLETTO LUGLI ${ }^{1}$

RESUMO: Este artigo demonstra a relação entre os gêneros textuais e a manifestação de verbos modais em textos traduzidos e considera o olhar para os gêneros de textos essencial ao ensino de língua estrangeira por meio da tradução. É uma pesquisa bibliográfica que identifica os significados de verbos modalizadores nas versões em português, espanhol e inglês do gênero decisão, publicado pelo Diário Oficial da União Europeia. Parte do princípio de que os gêneros textuais funcionam como instrumentos (DOLZ; SCHNEUWLY, 2004) para o trabalho com a interpretação e a produção de textos na tradução, que consiste em uma retextualização (TRAVAGLIA, 2003), transformação (ARROJO, 1993) do texto de partida. De acordo com essa perspectiva, este texto considera a relevância do estudo dos gêneros, dos verbos modais e da situação comunicativa no ensino de língua estrangeira via tradução, compreendendo que traduzir e aprender uma língua estrangeira não requerem apenas o domínio de capacidades linguísticas.

PALAVRAS-CHAVE: Modalizações. Gênero. Decisão.

RESUMEN: Este artículo demuestra la relación entre los géneros textuales y la manifestación de verbos modales en textos traducidos y considera esencial la mirada para los géneros de textos en la enseñanza de lengua extranjera por medio de la traducción. Es una investigación bibliográfica que identifica los significados de los verbos modalizadores en las versiones en portugués, español e inglés del género decisión, publicado por el Diario Oficial de la Unión Europea. Parte del principio de que los géneros textuales funcionan como instrumentos (DOLZ; SCHNEUWLY, 2004) para el trabajo con la interpretación y la producción de textos en la traducción, que consiste en una retextualización (TRAVAGLIA, 2003), transformación (ARROJO, 1993) del texto de partida. Desde esa perspectiva, este texto considera la relevancia del estudio de los géneros, de los verbos modales y de la situación comunicativa en la

${ }^{1}$ Universidade Estadual de Maringá (UEM), Maringá - PR - Brasil. Professora de Língua Espanhola. Departamento de Letras Modernas. Doutora em Letras. E-mail: vivianelugli@yahoo.com.br. 
enseñanza de lengua extranjera vía traducción y comprende que traducir y aprender una lengua extranjera no requieren únicamente el dominio de capacidades linguísticas.

PALABRAS CLAVE: Modalizaciones. Género. Decisión.

ABSTRACT: This article aims to present the relationship between text genres and the manifestation of modal verbs in translated texts and itendorses the view of text genres essential for learning a foreign language. It is a bibliographic research that identifies the meaning of modal verbs in Portuguese, Spanish and English versions of the decision genre, published by the Official Journal of the European Union. It is based on the principle that text genres work as instruments (DOLZ; SCHNEUWLY, 2004) for interpretation and text prodution in translation that consistes in the retextualization (ARROJO, 2003), in the transformation (ARROJO, 1993) of the source text. In accordance with this perspective, this article considers the relevance of the study of textual genres, modal verbs and communicative situations in the teaching of foreign languages via translation, understading that learning a foreign language and translating doesn't only require linguistic skills.

KEYWORDS: Modalization. Genres. Decision.

\section{Introdução}

Os gêneros textuais funcionam como instrumentos que permitem a produção, a compreensão e a interpretação de textos. São ferramentas semióticas mobilizadas em todas as ações linguageiras, razão pela qual Bajtín (2005) argumenta serem inúmeros.

Bajtín (2005, p. 248), ao conceber os gêneros como "enunciados ${ }^{2}$ relativamente estáveis" contempla essa variabilidade de formas e funções por eles manifestadas, dado que a sua existência revela uma necessidade humana e permeia todas as esferas de uso da língua.

Devido à sua amplitude de usos, formas e funções, o autor propõe diferenciá-los entre gêneros primários, como sendo aqueles que emergem nas esferas do cotidiano, e gêneros secundários, mobilizados nas situações mais elaboradas de uso da linguagem. $\mathrm{O}$ gênero, nosso objeto de análise neste artigo, é um exemplo de gênero secundário. Constitui-se como um gênero que apresenta características prototípicas de enunciados elaborados em situações mais complexas da comunicação verbal, por ser um gênero

\footnotetext{
${ }^{2} \mathrm{O}$ autor define enunciados como: "un eslabón en la cadena, muy complejamente organizada, de otros enunciados.” (BAJTÍN, 2005, p. 258).
} 
administrativo e normativo ${ }^{3}$, que integra o conjunto de textos escritos, de valor documental e orientador para os países eurocomunitarios.

Trata-se de um instrumento normativo que se refere a ações obrigatórias a serem efetuadas pelos países pertencentes aos Estados-Membros da Comunidade Europeia. Assim, direcionar o olhar para o teor desse tipo de gênero, especialmente para a compreensão dos verbos modais poder e dever, cuja função é a de modificar o significado do enunciado, torna-se relevante para o ensino/aprendizagem de tradução em aulas de línguas estrangeiras, pois a tradução inadequada de um modal pode gerar diferentes sentidos e consequências aos Estados-Membros.

Nesse sentido, é conveniente atentarmos para a geração de sentidos de modais, dado que a sua função é a de modificar o significado de um enunciado por meio do modus que consiste nas relações de verdade ou falsidade e afeta a relação entre sujeito e predicado. Ridruejo (2000) apresenta uma proposta de distinção entre o dictum/modus, pois para o autor toda ação é composta por um conteúdo e um modo de referir-se a esse conteúdo. Segundo essa compreensão, os modais demonstram o tipo de opção feita pelo falante para enunciar por meio de uma asseveração, desejo, ordem etc. Em um enunciado como "Los sellos de correos solo pueden usarse en el país que los emite, aunque el precio aparezca en euros", extraído de um folder ${ }^{4}$ da União Europeia, o verbo modal pueden expressa uma asseveração que indica uma obrigatoriedade, pois embora pueden indique permissão de usar os selos nos países que o emitem, não está autorizado utilizá-los em outros países. Nesse sentido, os modais modificam o significado dos enunciados.

Desse modo, os modais ocorrem nos mais diversos instrumentos semióticos, considerados gêneros textuais para imprimir forças enunciativas. Dolz, Gagnon e Decândio (2010) consideram instrumento o meio cultural construído pelo homem como sendo meios culturais de transformação. Os textos são, nesse sentido, instrumentos do agir humano, um meio pelo qual "as pessoas podem agir sobre o mundo e especialmente sobre os outros", segundo Fairclough (2001, p.91). São também meios de transformação, já que a função discursiva de um gênero textual pode ser tanto a de

${ }^{3}$ De acordo com González (2001), o gênero integra o conjunto de gêneros classificados como textos de Documentação Legislativa.

${ }^{4}$ Disponível em:

<http://www.injuve.es/sites/default/files/2015/29/publicaciones/Viajar\%20por\%20Europa\%20201516.pdf.> Acesso em: 21. Jul. 2017. 
transformar como a de reforçar dizeres. Nesse sentido, o gênero é um exemplo de texto instrumental que exerce uma ação sobre o outro por meio de verbos modais, de transformação de ações a serem realizadas pelos países do Bloco.

Conforme essa compreensão, gêneros textuais como esse nos motivam a uma avaliação atenta que leve em consideração as suas características, para, por meio delas, planejar o ensino de tradução em língua estrangeira, dado que a sua apropriação pelos aprendizes de uma língua demanda mediações docentes.

Consideramos, portanto, que resulta bastante válido para o ensino, não somente a reflexão sobre a composição estrutural do gênero, mas a análise mais ampla do gênero que envolve tanto a reflexão sobre o tema como as funções linguístico-discursivas de seus elementos textuais - os verbos modais poder e dever - , porquanto são verbos que podem expressar-se tanto em modalidades epistêmicas ${ }^{5}$ como deônticas $^{6}$ ou habilitativas ${ }^{7}$, sendo possível a sua desambiguização ${ }^{8}$ somente por meio da reflexão sobre o contexto.

Nesse sentido, ao concebermos como relevante a compreensão de verbos modais em gêneros textuais no ensino de línguas por meio da tradução no curso de Secretariado Executivo - visto que a formação de um secretário executivo deve contemplar não somente a formação para a atuação do profissional em instituições nacionais, mas também em organismos internacionais que oferecem amplas oportunidades na área de línguas $^{9}$ - guiamo-nos neste trabalho pela proposta do interacionismo sociodiscursivo (doravante ISD $)^{10}$ que não apenas considera o gênero como o meio pelo qual os sujeitos

${ }^{5}$ De acordo com Neves (2002), a modalidade epistêmica está relacionada às noções de absolutamente certo, necessidade e a possibilidade epistêmica, expressas por proposições contingentes, que dependem de como é o mundo.

${ }^{6}$ A modalidade deôntica, de acordo com Neves (2002), está relacionada com obrigações e permissões e com o traço lexical [+ controle].

${ }^{7}$ A modalidade disposicional ou habilitativa, para Neves (2002), está relacionada à disposição, habilitação, capacitação.

${ }^{8}$ Referimo-nos à desambiguização, pois o verbo "poder" é ambíguo em algumas situações, podendo apresentar tanto o sentido de possibilidade como em: i) "el chico puede caminar", pois este tem a possibilidade de fazer isso por morar perto de um parque (modalidade epistêmica); ii) a sua mãe lhe permitiu que caminhasse e, portanto, tem autorização para caminhar (modalidade deôntica); iii) o menino tem boa saúde e tem "capacidade" física para caminhar (modalidade habilitativa).

${ }^{9}$ As organizações internacionais como ONU, UNESCO, Instituições da União Europeia, trabalham com um amplo número de documentos que requerem traduções e, por isso, em alguns períodos oferecem vagas a freelances, fazendo contratos de duração limitada e, portanto, promovendo oportunidades aos profissionais competentes na área de tradução, entre os quais podem incluir-se os profissionais de Secretariado.

${ }^{10}$ A proposta a qual nos referimos é a proposta de análise de textos elaborada por Bronckart(1999) e Dolz e Schneuwly (2004). 
agem pela linguagem, mas nos fornece um modelo de análise de textos que direciona o nosso olhar para o desenvolvimento de capacidades de linguagem dos alunos nas atividades de produção e compreensão de textos.

O ISD é uma abordagem teórica e metodológica que considera as nossas ações como resultados de um processo de socialização. Nesse processo, nossas ações manifestam-se em forma de gêneros textuais, os quais também materializam as atividades dos aprendizes de uma língua estrangeira. Assim, as ações linguageiras ${ }^{11}$ materializadas pelos gêneros são caracterizadas como práticas sociais a serem estudadas como referenciais à aprendizagem efetiva de uma língua.

Destarte, ao ensinarmos a tradução em um curso para fins específicos, como o curso de Secretariado Executivo, torna-se sine qua non a escolha de gêneros, tal como, o gênero, por tratar-se de práticas sociais de referência para o ensino. Trata-se de um gênero autêntico, originado em instâncias enunciativas de poder, que precisa ser compreendido e traduzido devido ao seu valor informativo e normativo. Somando-se a isso é um gênero que não integra o grupo de gêneros trabalhados em livros didáticos no ensino de línguas.

\section{A tradução no ensino de língua estrangeira}

Concebendo a tradução como uma atividade complexa, uma retextualização (TRAVAGLIA, 2003), uma reformulação (OUSTINOFF, 2011) ou uma transformação (ARROJO, 1996), em que o papel do tradutor é o de mediar os interlocutores, não há como dissociar essa atividade da reflexão sobre a língua e no ensino de uma língua. Como afirma Gadamer (1997), 'traduzir é interpretar'. Logo, no ensino de uma língua estrangeira, ainda que inconscientemente, os aprendizes, ao mobilizarem a sua habilidade de interpretação, estão imperiosamente, traduzindo.

Talvez, por essa razão, García-Medall (2001) afirma que a tradução deve ser considerada uma habilidade a mais no ensino de língua estrangeira. Deve, segundo o autor, integrar os conteúdos de ensino desde os níveis mais elementares até o aperfeiçoamento do aluno na língua estrangeira. Tal afirmação reveste-se de sentido,

\footnotetext{
${ }^{11}$ As ações linguageiras, de acordo com Bronckart (2010, p.169), designam "o fato de que, em uma dada situação de comunicação, uma pessoa produz um texto, oral ou escrito, com um ou outro objetivo, para obter um ou outro efeito".
} 
pois a tarefa de traduzir implica analisar o sentido da textualização, procedimento que envolve vários conceitos e operações cognitivas associadas às capacidades dos alunos de solucionarem problemas com relação à linguagem, o que, conforme a teoria sociointeracionista que utilizamos, denominam-se capacidades de linguagem desenvolvidas pelos alunos.

García-Medall (2001) menciona vários autores que demonstram a importância de aliar a tradução pedagógica ao ensino de línguas, e cita Pegenaute (1996), que salienta a validade da tradução para a linguística descritiva e contrastiva, bem como para a formação intelectual do aprendiz.

Nesse contexto, entram em cena as mediações docentes que defendemos, o agir do professor voltado às necessidades de desenvolvimento de capacidades do aluno, agir no qual verifica, na língua estrangeira, quais capacidades o aprendiz de uma LE precisa desenvolver para compreender o sentido dos diferentes gêneros de textos que emergem nas diversas situações de interação e com os quais pode deparar-se em suas práticas sociais.

$\mathrm{Na}$ teoria sociointeracionista de trabalho com gêneros textuais a que nos filiamos e propomos para o ensino de línguas via tradução, há um esquema de três tipos de capacidades desenvolvido por Dolz, Pasquier e Bronckart (1993), e Dolz y Schneuwly (2004) a serem expandidas no ensino de produção e interpretação de textos. São elas: i) as capacidades de ação relacionadas às representações sobre o meio físico da interação comunicativa e o contexto de produção; ii) as capacidades discursivas referentes à observação do modo como se organiza a infraestrutura do texto, ou seja, os tipos de sequências textuais e tipos de discurso que o constituem; iii) as capacidades linguísticodiscursivas - relacionadas aos itens lexicais —, e os mecanismos de textualização e enunciativos, relacionados com a distribuição das vozes presentes nos textos e as expressões de modalizações com as quais se constroem enunciados.

Esses parâmetros de trabalho com o gênero propostos pelo ISD resultam válidos para sua aplicação ao ensino de línguas estrangeiras que visa à reflexão e à aprendizagem de tradução, pois permitem planejar o ensino de um modo integrado de desenvolvimento de habilidades, não considerando a língua isolada de seu contexto, mas como um artefato que atende às necessidades comunicativas que emergem nas 
práticas sociais. Nesse eixo de trabalho, concebe-se que a língua manifesta-se no gênero e o gênero comunica os sentidos por meio de sua textualização na tradução.

Desenvolver capacidades de linguagem em aulas de línguas estrangeiras por meio da tradução, cuja existência reflete a finalidade comunicativa de interação humana e que, portanto, faz parte do "labirinto infinito da linguagem" (ARROJO, 1986, p. 23), é uma condição sine qua non para o aprendiz aprender a lidar com a língua do "outro", pois a tradução de textos resultantes de práticas sociais de referência, como o gênero que selecionamos, é uma condição humana. É tão humana que emerge em uma esfera de poder, em um conjunto de textos ${ }^{12}$ de Documentação Legislativa, por exemplo, Regulamentos e Diretivas que impõem interpretações atreladas aos interesses da Comunidade nas quais emerge.

Hermans (1996), ao demonstrar a relevância da tradução, afirma que é sinônimo de compreensão e interpretação, noção, para nós, basilar no ensino de língua estrangeira, porquanto ser por meio da interpretação que interagimos com o outro nas situações diversas de interação.

Nessa perspectiva, ao concebermos a tradução como uma ação de linguagem atrelada a uma finalidade comunicativa indispensável, sobretudo em Organizações Internacionais nas quais os Secretários Executivos podem vislumbrar possibilidades de atuação, resulta totalmente favorável para o ensino de língua estrangeira, nesse curso, incluí-la entre os conteúdos da disciplina, uma vez que materializa gêneros como os selecionados neste artigo, considerados práticas autênticas de uso da linguagem para o ensino.

Concebendo a tradução, portanto, como uma retextualização ${ }^{13}$ (TRAVAGLIA, 2003) ou transformação (ARROJO, 1996) do texto de partida; compreendendo que o proceso tradutológico requer que o indivíduo como sujeito-leitor-autor recorra a arranjos linguístico-textuais e estruturais que correspondam aos seus objetivos, não somente de agir sobre o outro, mas de retextualizar o dito pelo outro, no sentido de tentar dizer o já dito a outros, não há como desvinculá-la, nas práticas de ensino, do estudo dos gêneros textuais.

${ }^{12}$ Arquitexto, de acordo com Bronckart (2010, p. 170), é definido como: o "conjunto dos modelos de gêneros em uso em uma determinada comunidade verbal, em uma determinada época de sua história, indexados, isto é, considerados como sendo adaptados a tal atividade ou a tal situação de comunicação." ${ }^{13}$ A retextualização, de acordo com Travaglia (2003), é compreendida como a produção de um novo texto em uma língua diferente daquela do texto de partida. 
Partindo do princípio defendido por Hermans (1996) de que a tradução e a compreensão caminham juntas, nosso objetivo, com este trabalho, é classificar a tradução como um tipo de atividade de retextualização sobre a qual resulta útil aos professores criarem consignas de leitura e escrita para a sua aprendizagem, desenvolvendo nos alunos capacidades de linguagem como sujeitos-leitores-tradutores.

Pasquier e Dolz (1996) defendem a necessidade de o professor dedicar tempo no ensino de línguas a atividades eficazes. Tal eficácia também está atrelada ao que Dora Riestra (2004) denomina "consignas", definidas pela pesquisadora como instruções de tarefas totalmente relacionadas com os efeitos que produzem na mente dos aprendizes. Segundo a autora, as consignas podem ser construídas pelos docentes e são planejadas e analisadas de modo sistemático como instrumentos a partir de uma perspectiva didática na qual a consigna exerce a função de uma ferramenta mediadora da atividade de ensino. Cabe, por conseguinte, ao professor o papel de mediador. Considerando o "interstício da compreensão" (SOBRAL, 2008), no qual se situa o aprendiz no processo de aprendizagem de uma língua estrangeira e, consequentemente, de tradução da mesma, torna-se fundamental a mobilização de recursos por meio de consignas adequadas ao nível de ensino e aos objetivos de aprendizagem dos alunos no ensino da língua estrangeira.

É nessa mobilização de recursos psicolinguísticos acionados pelo aluno, sujeitoleitor-tradutor para entender o outro e tentar retextualizar o "dito" ao outro, que a vertente teórica do ISD pode contribuir nas mediações docentes, por isso, em sua proposta para o ensino, as consignas/sequências didáticas exercem um papel central na apropriação das características dos gêneros textuais a serem compreendidos e traduzidos.

Neste artigo, no entanto, a fim de não nos estendermos com relação ao número de páginas, apresentamos uma única proposta de consigna para o ensino de língua estrangeira via tradução. Não trataremos de sequências didáticas, pois são mais extensas e completas.

Logo, deter-nos-emos a demonstrar como é possível trabalhar com os três eixos de capacidades de linguagem propostos por Dolz, Pasquier e Bronckart (1993), e Dolz e Schneuwly (2004), no gênero, disponível nas versões português, espanhol e inglês, no site da Comunidade Europeia. Salientamos que, dentre os mecanismos linguístico- 
discursivos relevantes para este trabalho na língua estrangeira, demos preferência aos verbos modais.

É apresentado, portanto, o estudo de verbos modais em traduções e no desenvolvimento de capacidades de linguagem dos aprendizes para lidar com a língua estrangeira, com o objetivo de situar o gênero textual e a tradução como práticas sociais que requerem um olhar atento no ensino de língua estrangeira por possibilitarem ao professor uma quebra de paradigmas no trabalho com a língua de forma isolada.

Partindo da concepção do ensino de tradução como uma atividade comunicativa (NORD, 1998), que se manifesta por meio de gêneros textuais, uma retextualização, a pesquisa apoia-se na proposta de análise de gêneros (BRONCKART,1999; DOLZ; SCHNEUWLY, 2004), de desenvolvimento de capacidades de linguagem (DOLZ; PASQUIER; BRONCKART, 1993; DOLZ; SCHNEUWLY, 2004) e na teoria funcionalista (NEVES, 2006; RIDRUEJO, 2000) para a análise dos tipos de verbos modais presentes na tradução do gênero .

Para alcançar nosso objetivo, guiamo-nos, neste artigo, pelas seguintes perguntas de pesquisa: I) quais são os verbos modais ${ }^{14}$ expressos no gênero; ii) que funções ${ }^{15}$ exercem?

\section{Definição da categoria modalidade}

Os verbos modais fazem parte da categoria de modalizadores que, de acordo com Neves (2006, p.154), "são usados na interação verbal, em princípio, para exprimir o ponto de vista do enunciador." É a concepção que adotamos para este trabalho, em conjunto com a definição de Ridruejo.

Ridruejo (2000) propõe entender modalidade como o reflexo da escolha que o falante faz para formular os diferentes tipos de enunciados, tais como, uma asseveração, uma pergunta, um desejo, uma ordem etc. $\mathrm{O}$ autor explica ser necessário, também, diferenciar a posição do falante quando estabelece uma asseveração, indicando não ter certeza sobre a realidade do que assevera ${ }^{16}$, e quando formula uma ordem ${ }^{17}$ ou desejo $^{18}$.

${ }^{14}$ Utilizamos a classificação de Neves (2002/2006) de modalização epistêmica e deôntica para as nossas análises.

${ }^{15}$ As funções a que nos referimos são: modalidade epistêmica ou deôntica.

${ }^{16}$ Nesse caso, estaria utilizando a modalidade epistêmica. 
Ridruejo (2000) considera que, para a análise da língua espanhola, é útil aproveitar a distinção entre modalidade epistêmica e modalidade deôntica. O linguista explicita que a modalidade epistêmica está vinculada às noções de conhecimento e crença. É, portanto, uma definição similar à de Neves (2006).

Já a modalidade deôntica, segundo Ridruejo (2000, p.3214), está relacionada à qualificação das condições em que se estabelece a verdade do predicado, nem sempre asseverado ou fatual. A diferença entre essa modalidade e a epistêmica é o fato de estar relacionada ao sistema de normas no qual pode atuar ora o agente da proposição, ora o falante.

Neves (2006), no tocante à enumeração dos tipos de modalizações, assevera que os modalizadores podem revestir-se de diferentes significados, formas e empregos. Para explicá-los, a autora enumera cinco tipos de modalidades: a) Modalidade alética ou lógica, relacionada com a verdade das proposições; b) Modalidade epistêmica, relacionada com a necessidade e a possibilidade; c) Modalidade deôntica, relacionada com obrigações e permissões; d) Modalidade volitiva, relacionada aos desejos do falante $^{19}$; e) Modalidade disposicional ou habilitativa, relacionada à habilitação, capacitação.

Neste estudo sobre os gêneros e os modais na tradução, deter-nos-emos a observar as duas das modalidades descritas por Ridruejo (2000), que apresentam características em comum com duas apresentadas em Neves (2006): as epistêmicas e as deônticas.

\section{Gêneros textuais e verbos modais no ensino de língua estrangeira}

As ações linguageiras materializadas pelos gêneros textuais são caracterizadas como práticas sociais. Os verbos modais, por sua vez, manifestam a atitude de falantes em meio a essas práticas, pois orientam a interpretação de enunciados, podendo levar a consideração de um enunciado como do tipo obrigatório, necessário, possível ou, ainda, manifestando sentido de capacidades ou desejos. São verbos que, segundo Ridruejo (2000), manifestam a posição do falante com relação ao conteúdo enunciado.

${ }^{17}$ Nesse caso, pode manifestar-se uma modalidade deôntica que pode expressar-se por meio do verbo deber.

${ }^{18}$ Nesse caso, a modalidade a ser manifestada seria uma volitiva.

${ }^{19}$ Segundo Neves (2006), ela é, no fundo, uma necessidade deôntica. 
Para Neves (2006), os enunciados portam marcas de subjetividade, de posicionamentos de seus enunciadores, e isso pode manifestar-se por meio dos modais que analisamos. Na teoria sociointeracionista, os modais inserem-se entre os mecanismos de textualização (BRONCKART, 1999) que configuram a organização dos gêneros textuais.

Portanto, estudar gêneros como práticas sociais autoriza o olhar para as marcas de subjevitidade e as orientações de interpretação de sentidos direcionados pelos modais presentes nos textos, considerando, igualmente, a cultura da língua na qual se manifestam tais práticas.

Vários autores consideram a tradução como prática social. Dentre eles, citamos Batalha e Pontes (2007) que consideram a tradução como "uma prática social comunicativa”. Fish (1992), embora não utilize a expressão prática social, considera a relevância do conhecimento da comunidade interpretativa na tradução, conceito que se encontra com o de prática social. De acordo com as postulações de Bajtín (2005), o social é indissociável da produção do enunciado, posto a razão para a elaboração de um enunciado ser o outro. Logo, as nossas ações discursivas dirigem-se sempre ao outro e, por assim ser, as traduções constituem-se autênticas práticas sociais.

Nesse sentido, nessa proposta de abordagem de ensino de língua estrangeira (doravante LE), por meio da tradução, o outro é considerado o núcleo das ações humanas. As ações acontecem a partir do outro, pelo outro e para o outro.

De acordo com essa concepção, consideramos que, dentre as formas linguísticotextuais relevantes no ensino de LE, por meio da tradução, em que o outro está no cerne da análise, destacam-se os verbos poder e dever, considerados modais por serem elementos reveladores das atitudes de falantes e pela sua possibilidade de apresentar polissemia de sentidos. São verbos que motivaram o estudo de vários pesquisadores em língua inglesa (PALMER, 1986; DE HAAN, 2005), em língua portuguesa (NEVES, 2006) e em língua espanhola (BRUNELLI; GASPARINI-BASTOS, 2012; RIDRUEJO, 2000; RINALDI, 2015).

O verbo poder, por exemplo, pode ser empregado, conforme Neves (2006), para expressar três sentidos diferentes: a) modalidade disposicional ou habilitativa, quando se refere à capacidade do sujeito de realização de uma tarefa; b) modalidade epistêmica, 
ao fazer referência a uma possibilidade; c) modalidade deôntica, ao referir-se à permissão ou proibição.

Para exemplificar, citamos um fragmento extraído de um folder disponível no site $^{20}$ da Comunidade Europeia:

(a)

\section{En persona}

En toda Europa hay cientos de centros locales de información sobre la Unión Europea. Puede encontrar la dirección del más cercano en este sitio web: www.europedirect.europa.eu

O verbo puede, presente na oração exemplificada, sugere tanto uma leitura de capacidade que possui o sujeito de encontrar o endereço mais próximo no site europedirect.europa.eu, quanto o sentido de possibilidade de encontrar o endereço dos centros de informação mais próximos. Para chegar a essa conclusão, seguimos o caminho analítico proposto por Neves (2000), de haver tipos de interpretações de verbos ambíguos como esse: i) um caminho é interpretar a oração por sua composição ou divisão. Nesse caso, ao interpretarmos a sequência modalizada pelo verbo poder por sua composição, pode-se gerar o sentido de possibilidade; ii) o caminho de interpretação por meio da divisão, no entanto, remete à ideia de capacidade que o turista tem de encontrar o endereço mais próximo, por meio do link especificado europedirect.europa.eu. Desse modo, é um verbo modal que, conforme a primeira interpretação, aponta para o sentido de modalidade epistêmica e, em um segundo tipo de interpretação, poderia ser compreendida como uma modalidade disposicional ou habilitativa.

Uma leitura diferente, no entanto, apresenta o verbo pueden no seguinte exemplo:

${ }^{20}$ Disponível em:

<http://www.injuve.es/sites/default/files/2015/29/publicaciones/Viajar\%20por\%20Europa\%20201516.pdf>. Acesso em: 20.jul.2017. 
Al cruzar las fronteras dentro de la UE, recibirá un mensaje

(b)

de su operador de móvil informándole de las tarifas por hacer
y recibir llamadas, enviar mensajes de texto y conectarse
a internet en el país al que vaya. Para evitar las facturas de
itinerancia desorbitadas, el volumen de datos que se pueden
descargar con un dispositivo móvil está limitado en todo el
mundo a 50 euros, a no ser que se tenga un límite predefinido.
Cuando llegue al $80 \%$ del límite recibirá un aviso.

Como é possível verificar, o exemplo demonstra que pueden permite apenas a leitura de permissão, sendo caracterizado como um verbo que indica uma modalidade deôntica. É um exemplo que reflete a função atribuída aos verbos modais de expressar atitudes, conforme Neves (2006), função conferida também ao verbo dever.

Como exemplo do verbo deber, transcrevemos os enunciados (c) e (d), extraídos de um folder publicado pela União Europeia ${ }^{21}$ :

(c)
Electricidad
Toda Europa utiliza corriente alterna de $220-240$ voltios y 50 ciclos. Aunque en Irlanda, Chipre, Malta y el Reino Unido se emplean clavijas cuadradas con tres patillas, en los demás países de la UE se usan por lo general clavijas con dos patillas. Las clavijas pueden variar, pero debería poder utilizar en cualquier lugar sus aparatos de dos patillas, como secadores de pelo, máquinas de afeitar, etc. En la mayoría de los aeropuertos y centros turísticos se pueden comprar adaptadores.

(d)

Los productos cosméticos deben indicar cuánto tiempo pueden utilizarse después de su apertura. Busque el símbolo del recipiente abierto.

${ }^{21}$ Extraído de:

<http://www.injuve.es/sites/default/files/2015/29/publicaciones/Viajar\%20por\%20Europa\%20201516.pdf>. Acesso em: 20.jul.2017. 
No exemplo (c), seguindo o caminho analítico de compreensão dos significados modais expostos por Neves (2006), a forma verbal debería poder direciona para uma leitura de necessidade, de modalidade epistêmica, pois afirma que as tomadas deveriam poder ser utilizadas em qualquer aparelho com dois orifícios. Esse tipo de interpretação ocorre devido ao fato de a forma verbal debería poder indicar uma sugestão para a realização da ação, refletindo, assim, o traço [- Controle].

Já no exemplo (d), seguindo o mesmo caminho analítico proposto por Neves (2006), o enunciado orienta para uma interpretação de modalidade deôntica, pois está presente o traço [+ Controle], uma vez ser obrigatória a indicação do tempo que o produto pode ser utilizado após ser aberto.

São verbos como esses, portanto, que constituem nosso objeto de estudo neste trabalho, em conjunto com o contexto de produção no qual se materializam.

Nosso olhar para essa categoria verbal deve-se ao fato de considerarmos relevante para o ensino de línguas o tratamento dos verbos modais como meios linguísticos possuidores não somente de uma categoria gramatical de pessoa, além de uma categoria de tempo que alude a uma relação de anterioridade, simultaneidade e posterioridade (ALARCOS LLORACH ${ }^{22}$, 2001, p.196), mas, também, de uma posição atitudinal.

Isso significa considerar que, no ensino de língua estrangeira, por meio da tradução, é viável e necessário refletir sobre as formas e funções dos signos presentes na língua, cabendo ao professor delinear consignas de tarefas que explorem não somente a capacidade de linguagem envolvida com a forma linguística (capacidade linguísticodiscursiva), mas também com os dois outros tipos de capacidades de linguagem (capacidades de ação e capacidades discursivas) dos alunos. A elaboração de consignas, nesse sentido, é praticável porque o trabalho com o gênero permite uma integração no ensino de línguas da análise do seu contexto de produção e dos verbos modais mecanismos enunciativos responsáveis pela distribuição de vozes no texto -, os quais, em conjunto, contribuem com a interpretação dos sentidos codificados no gênero traduzido.

Esse tipo de agir didático possibilita aos aprendizes perceberem ideias veiculadas pelos modais, como obrigação, possibilidade, pressuposição, necessidade,

${ }^{22}$ Autor representativo do funcionalismo espanhol. 
permissão, proibição etc; além de levá-los a entenderem questões pragmáticas envolvidas em sua manifestação no gênero. Trata-se de um modo de demonstrar aos estudantes que a língua sustenta o gênero, mas que os fatores pragmáticos ${ }^{23}$ advindos do contexto de produção ancoram o idioma e o texto a ser traduzido.

Hurtado-Albir (2016), ao referir-se à tradução pedagógica, também concebe os gêneros como relevantes no ensino de tradução. Gamboa Belisario (2004) ${ }^{24}$, partindo da concepção de ensino de tradução por meio desse instrumento, aponta que uma das finalidades das sequências didáticas é a de fomentar a reflexão sobre a tradução de gêneros. Neste trabalho, no entanto, compreendemos as consignas com o mesmo sentido de sequências didáticas, embora reconheçamos a diferença entre os conceitos de consigna e sequências, pois o dispositivo das sequências didáticas, como postulam Dolz, Gagnon e Decândio (2010, p.66), têm por objetivo, de um lado, focalizar uma situação de comunicação e as convenções de um gênero particular e, por outro, organizar e articular as diferentes atividades escolares, a fim de que as dificuldades dos aprendizes possam ser ultrapassadas.

Logo, as sequências didáticas são elaboradas a partir de um modelo didático do gênero escolhido como objeto de ensino, cujo propósito é o de desenvolver capacidades de linguagem nos alunos. Vários pesquisadores desenvolveram, no Brasil, esse tipo de artefato de ensino (CRISTOVÃO, 2007; CRISTOVÃO; NASCIMENTO, 2005; MACHADO et al 1999).

Pasquier e Dolz (1996) definem as sequências didáticas como ateliers de aprendizagem, nos quais se propõe uma série de atividades que tratam de resolver os problemas dos alunos, facilitando a conscientização das características linguísticas dos textos estudados.

As consignas, no entanto, não são como os ateliers, mas caracterizam-se como prescrições ou comandos elaborados pelo professor para mediar uma determinada atividade em sala de aula.

Com base no exposto, passamos à apresentação da análise dos verbos poder e dever presentes no gênero, demonstrando a possibilidade de aliar o estudo da língua

\footnotetext{
${ }^{23}$ Por fatores pragmáticos, entendemos aqui o escopo da tradução: a razão pela qual se traduz, quem traduz, para quem se traduz e em que momento e espaço físico e sociocultural isso acontece, conforme Nord (1998).

${ }^{24}$ Autora integrante do Grupo PACTE - grupo de estudos da Universidade Autônoma de Barcelona que investiga aspectos relacionados à aquisição e competência em tradução.
} 
estrangeira ao do gênero textual traduzido, de modo a desenvolver capacidades de linguagem nos alunos.

\section{Análise do gênero e dos verbos modais}

A interpretação de um texto é condição sine qua non para que o tradutor possa retextualizar (TRAVAGLIA, 2003) o documento fonte. A interpretação, entretanto, realiza-se imbricada aos fatores contextuais em que se realizam as traduções, relacionados às instruções recebidas pelo Departamento Geral de Tradução da Comissão Europeia (doravante $\mathrm{DGT}^{25}$ ), assim como prazo, ferramentas utilizadas na tradução etc. O conhecimento sobre o contexto de produção dos textos torna-se, nesse caso, significante para a análise do texto traduzido e a compreensão sobre as escolhas dos modais poder e dever na tradução.

De acordo com os três eixos de capacidades propostas por Dolz, Pasquier e Bronckart (1993), e Dolz e Schneuwly (2004), ao mobilizar-se o conhecimento referente aos fatores contextuais, o aluno estará desenvolvendo a sua capacidade de ação na língua estrangeira, uma vez que consegue refletir sobre a situação de produção do gênero.

Assim, tomando o gênero como objeto de estudo, propomos a consigna (i) ${ }^{26}$, com quatro comandos que poderiam incitar o aluno a refletir sobre o contexto, observando quem produz o gênero e em quais circunstâncias:

i) Observe o parágrafo seguinte do gênero ${ }^{27}$, refletindo sobre o momento de produção do gênero em que o mundo físico e social são partes indissociáveis e explique: a) as razões pelas quais se está tratando da comercialização do óleo de chia; b) o tipo de sequência textual em que emerge; c) os valores dos verbos poder nas três línguas; d) e as razões pelas quais esses verbos foram mobilizados.

${ }^{25}$ A equipe linguística do Departamento de Língua Portuguesa, sob a responsabilidade da Direção Geral de Tradução da Comissão Europeia, com o objetivo de contribuir para a normalização e a qualidade da tradução institucional, elaborou um guia para ser utilizado como modelo pelos tradutores. Está disponível em: <https://ec.europa.eu/info/sites/info/files/styleguide_portuguese_dgt_pt.pdf. Acesso em 21.jul.2017 . ${ }^{26}$ Adotamos a concepção de consigna de Dora Riestra (2004) de atividades elaboradas ao ensino para o desenvolvimento de capacidades dos alunos. Elas devem orientar o tipo de atividade cognitiva a ser realizada.

$27 \quad$ Disponível em: <http://eur-lex.europa.eu/legal-content/PT-ESEN/TXT/?uri=CELEX:32014D0890\&from=PT>. Acesso 10.jan.2017. 
Por meio dessa consigna, os aspectos contextuais estão relacionados ao mundo físico e social sobre os quais os alunos irão refletir, reflexão que lhes permitirá entender os motivos pelos quais se discute sobre a comercialização do óleo de chia na União Europeia.

No referente aos aspectos textuais, a consigna levará o aluno a refletir sobre o modo de organização do gênero, verificando se, nesse tipo de produção textual, predominam sequências textuais narrativas, descritivas, argumentativas, expositivas ou prescritivas.

Ao analisar os valores do verbo poder, no entanto, estará atentando a: aspectos linguístico-discursivos; aspectos contextuais, na identificação de valores, por exemplo, permissão, proibição, possibilidade, etc., uma vez que o uso do verbo está totalmente vinculado a questões de ordem pragmática; razões pelas quais foram acionados no texto.

Para exemplificar o parágrafo e a análise que motivaríamos a ser realizada pelo aluno por meio da consigna (i), transcrevemos os excertos no quadro 1:

Quadro 1: Parágrafo sobre a comercialização do óleo de chia em 3 versões para análise

\begin{tabular}{|c|c|c|}
\hline & 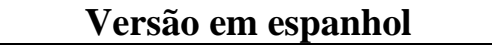 & \\
\hline $\begin{array}{l}\text { 1. O óleo de chia (Salvia } \\
\text { hispanica) tal como } \\
\text { especificado no anexo I pode } \\
\text { ser colocado no mercado da } \\
\text { União como novo ingrediente } \\
\text { alimentar para as utilizações e } \\
\text { nos níveis máximos definidos } \\
\text { no anexo II, sem prejuízo do } \\
\text { disposto na Diretiva } \\
2002 / 46 / \mathrm{CE}^{28} \text {. }\end{array}$ & $\begin{array}{l}\text { El aceite de chía (Salvia } \\
\text { hispanica) } \\
\text { puede } \\
\text { comercializarse en la Unión } \\
\text { como nuevo ingrediente } \\
\text { alimentario para los usos } \\
\text { definidos y en los niveles } \\
\text { máximos establecidos en el } \\
\text { anexo II, sin perjuicio de lo } \\
\text { dispuesto en la Directiva } \\
\text { 2002/46/CE. }\end{array}$ & $\begin{array}{l}\text { specified in Annex I may be } \\
\text { placed on the market in the } \\
\text { Union as a novel food } \\
\text { ingredient for the uses } \\
\text { defined and at the maximum } \\
\text { levels established in Annex II } \\
\text { without prejudice to the } \\
\text { provisions of Directive } \\
\text { 2002/46/EC. }\end{array}$ \\
\hline
\end{tabular}

Fonte: Elaboração própria.

Ao realizar a tarefa por meio da consigna (i), não somente com base no parágrafo apresentado no quadro, mas considerando todo o gênero textual, o aluno, para responder a pergunta (a) apresentada no comando da consigna, teria de mobilizar o seu conhecimento de mundo sobre o contexto de produção, momento que envolveria não apenas o conhecimento sobre o que é o gênero , mas também a análise de, pelo menos,

${ }^{28}$ Disponível em: <http://eur-lex.europa.eu/legal-content/PT/TXT/?uri=CELEX\%3A32014D0890>. Acesso em: 21.jul. 2017. 
três elementos: i) quem enuncia — mundo físico; ii) momento de produção; iii) contexto social envolvido.

Desse modo, em conjunto com o professor, o estudante buscaria informações sobre o gênero para entender que esse gênero é secundário, de uma esfera diretiva que envolve tanto a participação do Parlamento Europeu quanto do Conselho Europeu. Por se tratar de um documento dirigido aos Estados-Membros, cujo objetivo é a tomada de posições sobre propostas encaminhadas, precisa ser traduzido para registrar pareceres a serem consultados e acatados por todos os Estados-Membros.

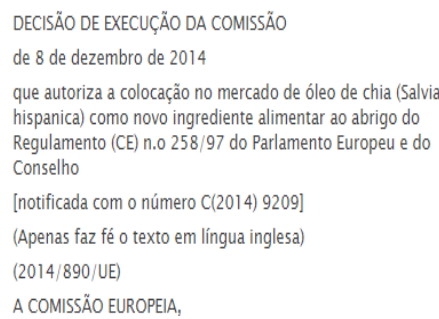

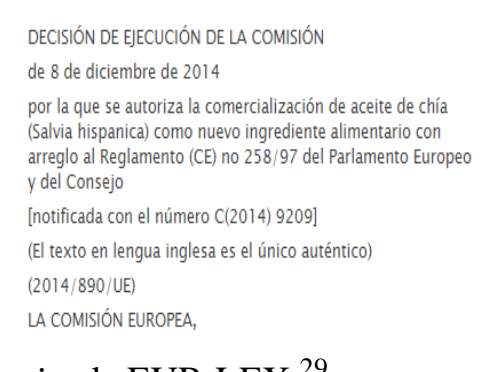

$$
\begin{aligned}
& \text { DECIS } \\
& \text { de } 8 \\
& \text { por } \\
& \text { (Salv } \\
& \text { arreg } \\
& \text { y del } \\
& \text { [notif } \\
& \text { (El te } \\
& \text { (201 } \\
& \text { LA COM }
\end{aligned}
$$

DECISIÓN DE EJECUCIÓN DE LA COMISIÓN
de 8 de diciembre de 2014
por la que se autoriza la comercialización de aceite de chía
(Salvia hispanica) como nuevo ingrediente alimentario con
arreglo al Reglamento (CE) no 258/97 del Parlamento Europeo
y del Consejo
[notificada con el número C(2014) 9209]
(El texto en lengua inglesa es el único auténtico)
(2014/890/UE)

ite da EUR-LEX. ${ }^{29}$

de partida para as versões em português e espanhol, a decisão deixa explícito que a única tradução que tem fé é a escrita em inglês, conforme é possível verificar na parte inicial da decisão.

Assim, quem enuncia é a Comunidade Europeia, a qual representa também o mundo físico no qual emerge o gênero. No entanto, a primeira redação foi materializada em língua inglesa. Logo, sendo um momento de produção em que os demais países integrantes da Comunidade Europeia manifestam interesse a respeito da produção e do consumo do óleo de chia, precisa ser vertida para as outras línguas, de modo a todos os Estados-Membros estarem cientes da prescrição referente ao seu modo de comercialização.

Somando-se a isso, é necessário considerar que o momento de produção da decisão foi o mês de dezembro de 2014, período em que a chia, apesar de já haver sido comercializada na alimentação com outras finalidades, passa a ser ainda mais explorada ${ }^{29} \quad$ Disponível
EN/TXT/?uri=CELEX:32014D0890\&from=PT>. Acesso em: 21.jul.2017. 
para o consumo e, nesse momento, como um tipo de óleo a mais a ser disponibilizado pelo mercado ${ }^{30}$.

O momento de produção, portanto, está associado ao contexto social envolvido, um momento em que a sociedade está cada vez preocupada com a saúde alimentar e a dieta adequada, resultando em desenvolvimento e consumo de inúmeros produtos que prometem uma vida mais saudável. A publicidade exposta a seguir demonstra que a semente chia entrou no mercado prometendo vantagens ao consumidor:

Figura 1: Publicidade

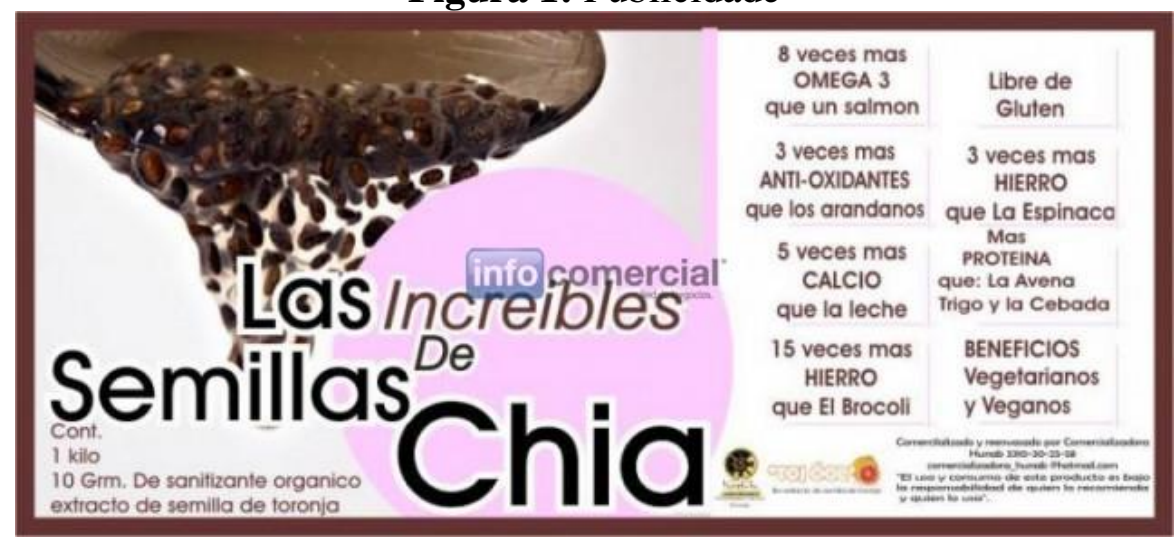

Fonte: <http://www.infocomercial.com/p/semillas-de-chia-las-increibles-_148507.php>. Acesso em: 04. jan. 2017.

Desse modo, seria possível desenvolver as capacidades de ação nos alunos por meio de uma consigna de ensino de língua estrangeira, tendo como viés o estudo de textos traduzidos por meio de gêneros que contribuem na compreensão dos fatores pragmáticos como esse - momento em que é moda ${ }^{31}$ aderir-se às dietas — que sustentam as formas linguísticas e a emergência de gêneros.

${ }^{30}$ A escolha do gênero neste trabalho deve-se ao fato de que a seleção dos gêneros textuais a serem selecionados para o estudo de línguas estrangeiras no curso de Secretariado Executivo precisa dialogar com as necessidades mercadológicas, pois o profissional de Secretariado é formado para atuar nas diferentes esferas de trabalho, nacionais ou internacionais. Logo, o seu conhecimento sobre documentos que tratam de liberação de produtos a serem comercializados passa ser fundamental em sua formação por serem requeridas, pelo menos, capacidades de leitura desse tipo de gênero nas instituições em que podem vir a atuar.

${ }^{31}$ Sendo a publicidade um gênero cuja finalidade é atrair a atenção do leitor, o aluno estaria, por meio desse gênero, observando o modo como se chama a atenção para as sementes de chia, ou seja, por meio do destaque a elas atribuído; estaria ao mesmo tempo observando que abundam orações sem verbos, com características semânticas de sentido positivo, por meio de elementos como más... que, além dos numerais que indicam quantidade de aspectos positivos no consumo. Esse tipo de leitura contribuiria, igualmente, com o desenvolvimento de capacidades de ação e linguístico-discursivas dos aprendizes. 
Para desenvolver as capacidades discursivas, no entanto, o professor trabalharia com a segunda questão do comando da consigna, de modo a levar o aluno a entender os tipos de sequências textuais que há no gênero e classificar a sequência textual em que estão inseridos os modais poder e dever.

Esse comando sobre as sequências é relevante, pois Bronckart (1999) considera que um gênero textual é considerado uma unidade divisível, uma vez ser possível decompor as suas partes em sequências textuais. Essas sequências, consideradas um nível intermediário entre frases e textos, e reconhecidas por marcas linguísticas que concretizam os gêneros, podem ser classificadas em cinco tipos, devido ao seu caráter dialógico: narrativa, descritiva, argumentativa, explicativa e prescritiva.

Assim, ao analisar-se o gênero decisão, será possível observar tratar-se de um gênero composto por sequências explicativas, descritivas e prescritivas, porque, anteriormente ao parecer do Parlamento, há toda uma introdução do texto na qual se explica o contexto que conduziu ao resultado de tal decisão, como podemos ver nos excertos seguintes:

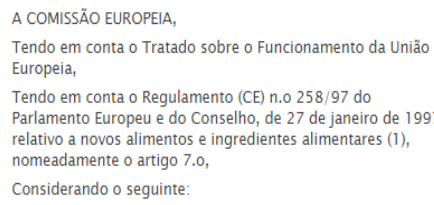

Fonte:

Extraído

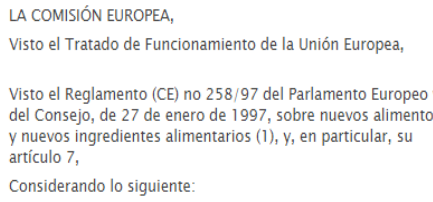

de:
THE EUROPEAN COMMISSION,

Having regard to the Treaty on the Functioning of the European Union,

Having regard to Regulation (EC) No 258/97 of the European Parliament and of the Council of 27 January 1997 concerning novel foods and novel food ingredients (1), and in particular Article 7 thereof,

Whereas:

ESEN/TXT/?uri=CELEX:32014D0890\&from=PT>. Acesso em: 21. jul. 2017.

Os excertos demonstram que, no primeiro parágrafo do gênero decisão, há uma sequência explicativa por demonstrar que, ao proferir-se o documento, foi levado em consideração o Regulamento (CE) no. 258/97 do Parlamento Europeu referente aos novos alimentos e ingredientes alimentares. Além disso, foi considerado que, em 12 de novembro de 2012, a empresa Functional Products Trading S.A apresentou um pedido às autoridades do Reino Unido para colocarem o óleo de chia no mercado. Somente após essas explicações e outras que a seguem ${ }^{32}$, surgem as sequências prescritivas do parecer como a constante no quadro 1.

${ }^{32}$ As informações que seguem são: a emissão do relatório inicial em 8 de julho pelo órgão competente do Reino Unido, a emissão desse relatório aos demais Estados-Membros da Comissão, as objeções apresentadas e a da Comissão, os requisitos relativos ao suplemento alimentar e a conformidade de medidas de acordo com o parecer do Comitê Permanente dos Vegetais, Animais e alimentos para o consumo humano e animal. 
Logo, a sequência "O óleo de chia (Salvia hispanica) tal como especificado no anexo I pode ser colocado no mercado da União como novo ingrediente alimentar...” caracteriza-se como uma sequência prescritiva que autoriza a comercialização do óleo de chia.

O fato de o verbo modal pode, puede, may estarem inseridos em uma sequência prescritiva aponta para uma leitura de permissão nesse contexto, todos com os mesmos efeitos expressivos nas línguas portuguesa, espanhola e inglesa. Desse modo, o aluno já estaria respondendo às questões " $b$ " e "c" da consigna e desenvolvendo suas capacidades discursivas ao identificar as sequências textuais. Ao mesmo tempo, desenvolveria capacidades linguístico-discursivas ao refletir sobre os valores do verbo modal poder que funciona como um auxiliar nas três línguas e não poderia gerar outra interpretação, nesse contexto, que não a de permissão. Além do mais, a capacidade linguístico-discursiva também será desenvolvida quando o estudante percebe a manifestação de impessoalidade na oração, característica representativa do gênero dessa esfera diretiva.

A decisão é, portanto, um gênero da ordem do expor-instruir, informativoautoritativo, em que a responsabilidade do dizer é atribuída a uma instância representativa da Comissão Europeia. Por isso, não há marcas do enunciador (BRONCKART, 1999). O reconhecimento dessa característica do gênero também está relacionado às capacidades discursivas - parágrafos que expressam ações a serem realizadas - e de ação — quando o aluno reconhece a instância enunciativa (União Europeia) que emite a informação.

Concomitantemente a essa análise, o aluno, por meio da mobilização dos três eixos de capacidades ${ }^{33}$, entenderia a razão pela qual o modal foi traduzido por pode em português e puede em espanhol, pois a tradução, de acordo com a orientação da DGT, deve seguir o padrão estilístico do texto de partida que foi redigido na língua inglesa.

Além disso, no tocante ao mundo socio-subjetivo que também se reflete no texto, o aluno, ao mobilizar a sua capacidade de ação, entenderia que esse mundo é representado pelos membros da Comissão Europeia que ditaram o documento original

\footnotetext{
${ }^{33}$ Por sua capacidade de ação - ao ter compreendido que o texto fonte foi produzido em inglês —; por meio da capacidade discursiva, que permite ao aluno identificar que sequências prescritivas causam efeito de autoridade e devem ser atendidas; e por meio da capacidade linguístico-discursiva que lhe dá subsídios para entender que may é um modal em inglês utilizado para indicar permissão.
} 
para os tradutores junto ao Departamento Geral de Tradução (DGTs), órgão responsável pela retextualização dos documentos elaborados no âmbito da Comissão Europeia.

Por conseguinte, as razões pelas quais esses verbos foram mobilizados encontram-se na própria característica do gênero de utilizar verbos que indicam permissão ou dever e no contexto de produção do gênero que precisa seguir pautas de instruções da DGT.

Dessa forma, o trabalho com o ensino da língua estrangeira como uma língua de comunicação internacional poderia ser feito em sala de aula, partindo do gênero para os modais, de modo a demonstrar aos alunos que os modais são verbos especialmente relevantes em uma tarefa de tradução por refletirem atitudes e vozes dos agentes envolvidos na enunciação, resultando, quase sempre, em uma tradução literal ${ }^{34}$ dos textos de esferas especializadas, como a decisão, inscrita na esfera Parlamentar.

Assim, devido ao limite de páginas deste trabalho, limitamo-nos a demonstrar, por meio de alguns exemplos, a maneira como os modais foram traduzidos no gênero.

\section{A expressão de verbos modais na tradução do gênero decisão}

Estamos cientes de que, na tradução, pode haver escolhas e aproximações de sentidos que acontecem por meio da interpretação do texto. Ao considerarmos a tradução uma retextualização, entendemos que o tradutor, ao retextualizar, também pode ressignificar ${ }^{35}$ e transformar (ARROJO, 1993) o texto.

Nesse processo, abre-se um espaço para a escolha de signos linguísticos que fazem parte de uma língua e de uma cultura, que representa uma determinada comunidade interpretativa (FISH, 1992), manifestando, em ocasiões, a diferença (RODRIGUES, 2000).

Com esse olhar, analisamos a manifestação das modalizações realizadas por meio dos verbos modais no gênero decisão.

Para demonstrá-las expomos os seguintes quadros:

34 A noção de tradução literal que adotamos é a mesma de Hurtado-Albir (2016), ao referir-se aos métodos de tradução, ou seja, de uma tradução em que se traduz palavra por palavra, em que se reproduz o sistema linguístico de partida.

${ }^{35}$ Ressignificar é aqui compreendido como significar por uma segunda vez, por meio de elementos textuais correspondentes ao do texto de partida. 
Quadro 2: Verbo modal deber em 3 versões

\begin{tabular}{|c|c|c|}
\hline Versão em português & Versão em espanhol & Versão em inglês \\
\hline $\begin{array}{l}\text { Em conformidade com o } \\
\text { artigo 7.o, n.o } 1, \quad \text { do } \\
\text { Regulamento } \\
\text { n.o } 258 / 97 \text {, deve ser adotada } \\
\text { uma decisão de execução da } \\
\text { da Comissão que tenha em } \\
\text { conta as objeções } \\
\text { apresentadas. }\end{array}$ & $\begin{array}{l}\text { De conformidad con el } \\
\text { artículo } 7 \text {, apartado 1, del } \\
\text { Reglamento (CE) no 258/97, } \\
\text { debe adoptarse una Decisión } \\
\text { de Ejecución de la Comisión } \\
\text { que tenga en cuenta las } \\
\text { objeciones planteadas. }\end{array}$ & $\begin{array}{l}\text { In accordance with Article } \\
7(1) \text { of Regulation (EC) No } \\
258 / 97 \text { a Commission } \\
\text { Implementing Decision } \\
\text { should be made that takes } \\
\text { into account the objections } \\
\text { raised. }\end{array}$ \\
\hline
\end{tabular}

Fonte: Elaboração própria. Excerto extraído de <http://eur-lex.europa.eu/legal-content/PT-ESEN/TXT/?uri=CELEX:32014D0890\&from=PT>. Acesso em: 21.jul.2017.

Como é possível observar, os modais presentes no parágrafo ilustrado refletem uma ordem, uma prescrição, por tratar-se de uma informação amparada pelo Regulamento (CE) $\mathrm{n}^{\circ}$ 258/97 e reflete, por conseguinte, o traço [+ controle], caracterizando, desse modo, uma modalidade deôntica por indicar uma obrigatoriedade. Esse efeito causado no texto de obrigatoriedade explica-se e pode ser compreendido pelo aluno, ao fazer a leitura dos três considerandos que antecedem a esse. No considerando 1, explica-se que a empresa Functional Products Trading S.A. apresentou um pedido às autoridades competentes do Reino Unido para colocar óleo de chia no mercado. $\mathrm{O}$ considerando 2 explicita ter sido emitido o relatório de avaliação inicial, no qual se conclui que o óleo de chia (Salvia hispanica) preenche os critérios aplicáveis aos novos alimentos estabelecidos no artigo 3.o, n.o 1, do Regulamento (CE) n.o 258/97. O terceiro considerando demonstra que a Comissão transmitiu o relatório de avaliação inicial aos demais Estados-Membros. Apenas no considerando 4, demonstrou-se que foram apresentadas objeções. É referente a essas objeções que, no considerando 4, exige-se adotar uma da Comissão que leve em conta as objeções apresentadas. Trata-se, portanto, de uma tradução literal, método utilizado na tradução devido à prescrição contida na DGT referente aos modais.

Quadro 3: Verbo modal deber em 3 versões

\begin{tabular}{|c|c|c|}
\hline & & \\
\hline $\begin{array}{l}\text { A utilização de óleo de chia } \\
\text { (Salvia hispanica) deve ser } \\
\text { autorizada sem prejuízo das } \\
\text { disposições previstas nessa } \\
\text { legislação. }\end{array}$ & $\begin{array}{l}\text { Debe autori } \\
\text { utilización de ac } \\
\text { (Salvia hispar } \\
\text { perjuicio de los }\end{array}$ & $\begin{array}{l}\text { The use of chia } \\
\text { hispanica) sh } \\
\text { authorised witho } \\
\text { to the requireme } \\
\text { legislation. }\end{array}$ \\
\hline
\end{tabular}

Fonte: Elaboração própria. Excerto extraído de <http://eur-lex.europa.eu/legal-content/PT-ESEN/TXT/?uri=CELEX:32014D0890\&from=PT>. Acesso em: 21.jul.2017. 
O excerto exemplificado no quadro três reflete, também, uma prescrição, uma ação a ser realizada por meio de uma ordem, demonstrando, assim, o traço [+ controle]. Está presente, portanto, a modalização deôntica nas três línguas.

Quadro 4: Verbo modal deber em 3 versões

\begin{tabular}{|c|c|c|}
\hline Versão em português & Versão em espanhol & Versão em inglês \\
\hline $\begin{array}{l}\text { A designação do óleo de } \\
\text { chia autorizada pela } \\
\text { presente Decisão a utilizar } \\
\text { na rotulagem dos gêneros } \\
\text { alimentícios que o } \\
\text { contenham deve ser «óleo } \\
\text { de chia (Salvia hispanica)» }\end{array}$ & $\begin{array}{l}\text { La denominación del aceite } \\
\text { de chía autorizado por la } \\
\text { presente Decisión en el } \\
\text { etiquetado de los productos } \\
\text { alimenticios que lo } \\
\text { contengan será «aceite de } \\
\text { chía (Salvia hispanica)». }\end{array}$ & $\begin{array}{l}\text { The designation of chia oil } \\
\text { authorised by this Decision } \\
\text { on the labelling of the } \\
\text { foodstuffs containing it } \\
\text { shall be 'Chia oil (Salvia } \\
\text { hispanica)'. }\end{array}$ \\
\hline
\end{tabular}

Fonte: Elaboração própria. Excerto extraído de <http://eur-lex.europa.eu/legal-content/PT-ESEN/TXT/?uri=CELEX:32014D0890\&from=PT> . Acesso em: 21. jul. 2017.

O exemplo do quadro quatro demonstra que, na versão em língua espanhola, optou-se pelo uso do verbo "ser" no futuro, pois esse verbo também tem valor de autoridade, conforme Alarcos Llorach (2001). O autor salienta que a análise do tempo verbal é importante para a compreensão da tradução de modalidades por meio de verbos modais, visto que, como afirma Neves (2006), em enunciados relativos a eventos futuros, por via de regra, a interpretação é de raiz, ou seja, deôntica.

No entanto, não podemos afirmar que "será", no excerto transcrito em espanhol, apresenta o mesmo valor de modalidade deôntica apresentada pelos modais devem e shall. Isso porque "será" não é um modal. Porém, reconhecemos ser uma versão que atende aos efeitos comunicativos esperados: o de prescrever o modo de designação do óleo de chia.

\section{Considerações finais}

Como podemos observar nos quadros dois a quatro, os modais utilizados na textualização permitem uma leitura de modalidade deôntica por expressarem obrigação, ordem/ações a serem realizadas pelos agentes destinatários da decisão.

É importante considerar que, com exceção do quadro quatro, na versão em língua espanhola, a tradução foi do tipo literal. Isso porque, nas traduções realizadas pela Comunidade Europeia, para que a função comunicativa do texto a ser traduzido 
seja alcançada, o DGT elaborou um guia para os tradutores de espanhol e de português em que há informações relacionadas ao estilo de língua a ser usada, com base em textos em inglês, pois é o texto em inglês, com frequência, o de partida.

Resta ao tradutor, consequentemente, a responsabilidade de interpretação do documento a ser traduzido, dado que ele é o leitor-autor responsável pela retextualização da tradução e, a partir de sua interpretação, escolhe os mecanismos linguístico-discursivos que melhor atendam ao sentido e às prescrições de tradução determinadas pelo guia da DGT.

Nesse contexto de agir docente por meio de consignas de trabalho com o gênero e os modais, o ensino de LE via tradução resultaria bastante útil por tomar o gênero traduzido como modelo de referência para as práticas escolares.

\section{REFERÊNCIAS}

ALARCOS LLORACH, E. Gramática de la lengua española. Real Academia Española. Colección Nebrija y Bello. Madrid: Espasa Calpe, S.A, 2001.

ALBIR, A. H. Traducción y traductología. Introducción a la traductología. Madrid: Cátedra, 2016.

ARROJO, R. As relações perigosas entre teoria e políticas de tradução. In: Tradução, desconstrução e psicanálise. Rio de Janeiro: Imago, 1993.

BAJTÍN, M. Estética de la creación verbal.1 ed. Buenos Aires: Siglo XXI Argentina, 2005.

BATALHA, M. C.; PONTES JR., G. Tradução. S. Paulo: Vozes, 2007.

BELISARIO, G. L. La traducción como destreza de mediación: hacia la construcción de una competencia plurilingüe e pluricultural en el estudiante de E/LE”. 221f. 2004. Dissertación (Máster en Enseñanza del Español como Lengua Extranjera). Universidad Antonio de Nebrija, Madrid, 2004.

BRONCKART, J. P. Atividades de linguagem, textos e discursos: por um interacionismo sócio-discursivo. Tradução de Anna Rachel Machado e Péricles Cunha. São Paulo: Educ, 1999.

BRONCKART, J. P. Gêneros de textos, tipos de discurso e sequências. Por uma renovação do ensino da produção escrita. Letras, Santa Maria, v. 20, n. 40, p. 163-176, jan.jun.2010. 
BRUNELLI, A. F.; GASPARINI-BASTOS, S. D. A manifestação das diferentes modalidades no emprego do verbo modal poder em português e em espanhol:análise do discurso de autoajuda. Signo y Sena, número 22, diciembre de 2012, p. 165-180, Facultad de Filosofía y Letras (UBA).

\section{COMISSÃO EUROPEIA DIREÇÃO GERAL DA TRADUÇÃO. Documento do} Departamento de Língua Portuguesa da Direção-Geral da Tradução da Comissão Europeia. 3 ed., jun. 2015.

CRISTOVÃO, V. L. L.; NASCIMENTO, E. L. Gêneros textuais e Ensino: Contribuições do interacionismo sócio-discursivo. In: KARWOSKI, A. M.;

GAYDECZKA, B; BRITO, K. S. (orgs). Gêneros Textuais: reflexões e ensino. Palmas e União da Vitória, Pr: Kaygangue, 2005.

CRISTOVÃO, V. L. L. Modelos didáticos de gêneros: uma abordagem para o ensino de língua estrangeira. Londrina: UEL, 2007.

DE HAAN, F. Typological approaches to modality. In: FRAWLEY, W. Modality. Berlin: Mouton de Gruyter, 2005.

DIARIO OFICIAL DE LA UNIÓN EUROPEA. Disponível em: <http://eurlex.europa.eu/legal-content/PT-ES-EN/TXT/?uri=CELEX:32014D0890\&from=PT>. Acesso em: 10 jan. 2017.

DIREÇÃO-GERAL DA TRADUÇÃO DA COMISSÃO EUROPEIA. Documento do departamento de língua portuguesa da direção-geral da tradução da comissão europeia. 2. ed. ampliada: jan. 2012. Disponível em:

$<$ http://ec.europa.eu/translation/portuguese/guidelines/documents/styleguide_portugues e_dgt_pt.pdf >. Acesso em: 10 jan. 2015.

DOLZ, J.; PASQUIER, G.; BRONCKART, J. P. A aquisição do discurso: emergência de uma competência ou aprendizagem de capacidades linguageiras diversas. Estudos de Linguística Aplicada, n. 89, p. 25-35, 1993.

DOLZ, J.; SCHNEUUWLY, B. Gêneros orais e escritos na escola. Tradução de Roxane Rojo e Glaís Sales Cordeiro. Campinas: Mercado de Letras, 2004.

DOLZ, J.; GAGNON, R.; DECÂNDIO, F. Produção escrita e dificuldades de aprendizagem. Tradução Fabrício Decândio e Anna Rachel Machado. Campinas, SP: Mercado de Letras, 2010.

FAIRCLOUGH, N. Discurso e mudança social. Brasília: Editora Universidade de Brasília: Editora UnB, 2001.

FISH, S. Is there a text in this class? Tradução de Rafael Eugenio HOYOSANDRADE. Alfa, São Paulo, 36: 189-206, 1992. 
GADAMER, H-G. "A linguagem como medium da experiência hermenêutica". In: Verdade e método I. Trad. Flávio Paulo Meurer. Petrópolis: Vozes, 1997. 497-631.

GARCÍA-MEDALL, J. La traducción en la enseñanza de lenguas. Hermeneus. Revista de Traducción e Interpretación, n.3, 2001, p. 113-140, Universidad de Valladolid.

GASPARINI-BASTOS, S. D. Os constituintes extrafrasais com valor epistêmico: análise de entrevistas jornalísticas no espanhol e no português. Araraquara: 2004. 161f. Tese (Doutorado em Linguística), Faculdade de Ciências e Letras, Universidade Estadual Paulista, 2004.

GONZÁLEZ, Y. M. La documentación de la Unión Europea: concepto y clasificación. BID, n. 7, dez. 2001.

HERMANS, T. Translation's other. Inaugural lecture. London: UCL, 1996.

MACHADO, A. R. Um instrumento de avaliação de material didático com base nas capacidades de linguagem a serem desenvolvidas no aprendizado de produção textual. In: Intercâmbio, vol. x, p. 137-147, 2001.

NEVES, M. H. de M. Imprimir marcas no enunciado. Ou: A modalização na linguagem. In: NEVES, M. H. de M. Texto e Gramática. São Paulo: Contexto, 2006.

NEVES, M. H. de M. A modalidade. In: Koch, I. V.(org). Gramática do Português Falado. 2 ed. Campinas, São Paulo: Editora da Unicamp, 2002.

NORD, C. La unidad de la traducción en el enfoque funcionalista. Quaderns. Revista de traducció 1, 1998, p. 65-77.

OFICINA DE PUBLICACIONES. Viajar por Europa. Folleto. Disponível em: $<$ http://www.injuve.es/sites/default/files/2015/29/publicaciones/Viajar\%20por\%20Euro pa\%202015-16.pdf>. Acesso em: 20 jul.2017.

OUSTINOFF, M. Tradução. História, teorias e métodos. Tradução de Marcos Marcionilio. São Paulo: Parábola, 2011.

PALMER, F. R. Mood and modality. Cambridge University Press, 1986.

PASQUIER, A.; DOLZ, J. Um Decálogo para Ensinar a Escrever.Cultura y Educación. Tradução provisória de Roxane Helena Rodrigues Rojo. Madrid: Infancia y aprendizaje, n. 2, p. 31-41, 1996.

RIDRUEJO, E. Modo y modalidad. El Modo em las subordinadas sustantivas. In: BOSQUE, I.; DEMONTE, V. Gramática descriptiva de lengua española. Las construcciones sintácticas fundamentales. Relaciones temporales, aspectuales $\mathbf{y}$ modales. Madrid: Espasa Calpe, 2000. 
RIESTRA, D. Las consignas de trabajo en el espacio sócio-discursivo de la enseñanza de la lengua. Tesis de Doctorado, no. 328, Suiza, Universidad de Ginebra, 2004.

RINALDI, N. Um estudo sobre os diferentes valores modais do verbo 'Poder' em entrevistas jornalísticas do espanhol. 2015. 125 f. Dissertação (Mestrado em Estudos Linguísticos) - Instituto de Biociências, Letras e Ciências Exatas, Universidade Estadual Paulista, São José do Rio Preto, Unesp, 2015.

RODRIGUES, C. C. Tradução e diferença. S. Paulo: Unesp, 2000.

SOBRAL, A. Dizer “o mesmo" a outros: ensaios sobre tradução. São Paulo: SBS, 2008.

TRAVAGLIA, N. G. Tradução e retextualização: a tradução numa perspectiva textual. Uberlândia: EDUFU, 2003.

\section{Como referenciar este artigo}

POLETTO LUGLI, Viviane Cristina. A expressão de verbos modais na tradução do gênero decisão: contribuições para o ensino de língua estrangeira. Rev. EntreLínguas, Araraquara, v. 3, n. 2, p. 248-275, jul./dez. 2017. Disponível em:

<https://doi.org/10.29051/rel.v3.n2.2017.9474>. E-ISSN: 2447-3529.

Submetido em: 28/02/2017

Revisões requeridas: 02/06/2017

Aprovado em: 01/08/2017 